Supplement of Atmos. Meas. Tech., 14, 6723-6748, 2021

https://doi.org/10.5194/amt-14-6723-2021-supplement

(C) Author(s) 2021. CC BY 4.0 License.

(c) (1)

Atmospheric
Measurement
Techniques

Supplement of

\title{
Estimates of mass absorption cross sections of black carbon for filter- based absorption photometers in the Arctic
}

\section{Sho Ohata et al.}

Correspondence to: Sho Ohata (sho.ohata@isee.nagoya-u.ac.jp)

The copyright of individual parts of the supplement might differ from the article licence. 
(a)

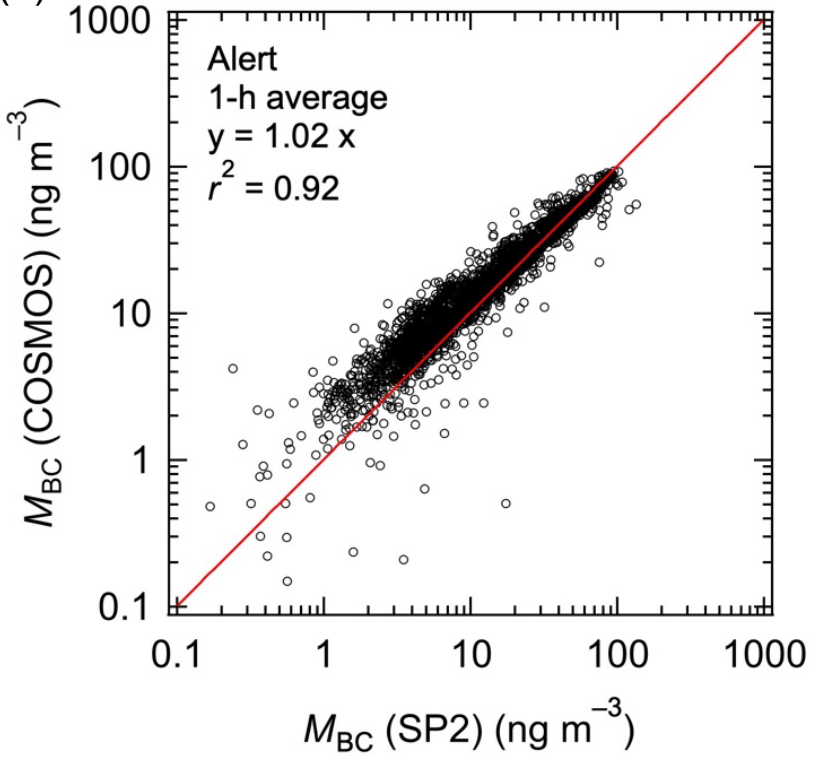

(b)

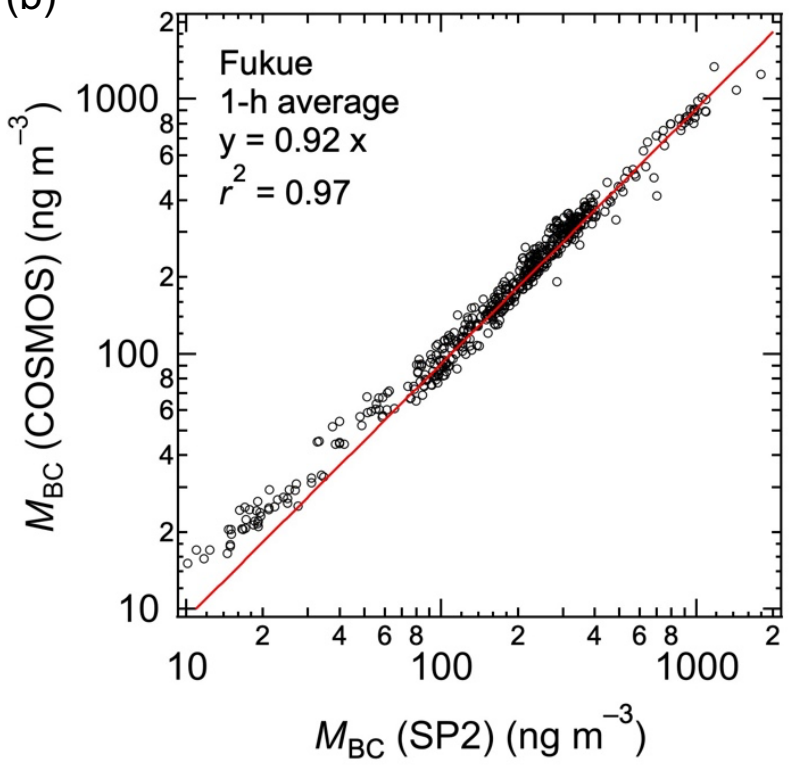

Figure S1. Correlation of $M_{\mathrm{BC}}$ measured by COSMOS and SP2 at (a) Alert and (b) Fukue. The axes are on a logarithmic scale. The solid line in the correlation plot is the least squares regression forced through the origin. 
(a)

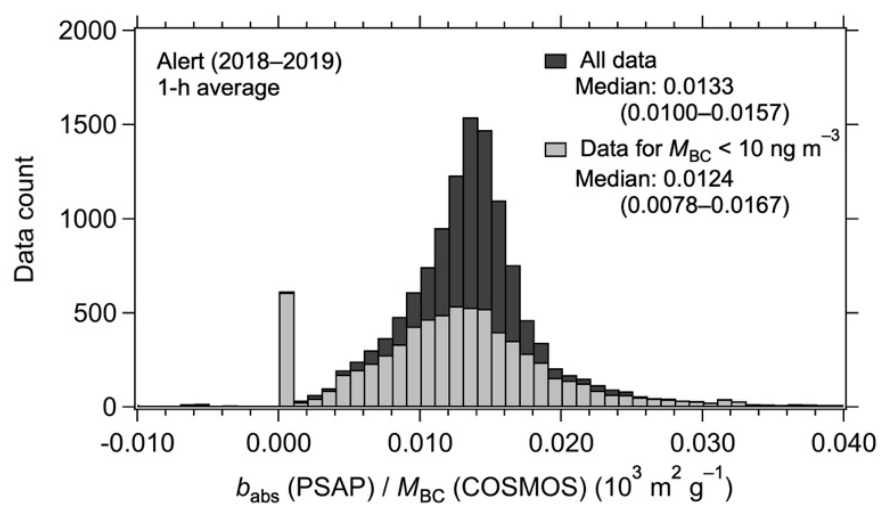

(b)

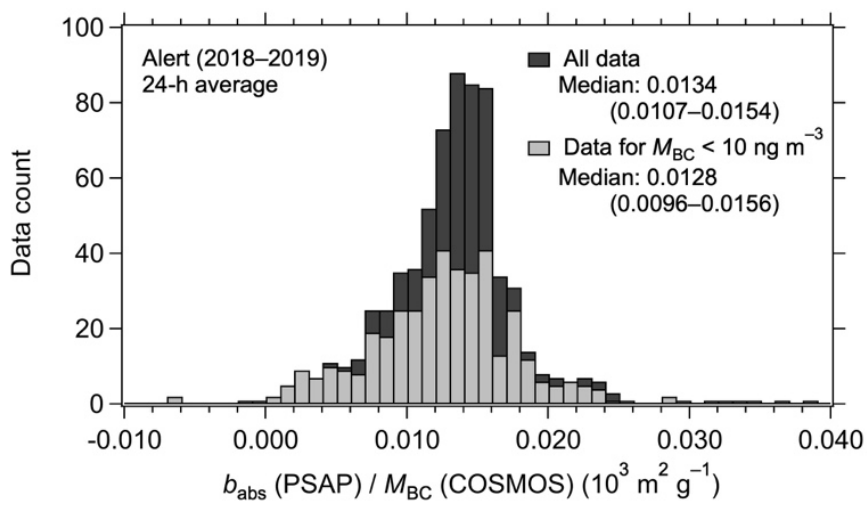

10 Figure S2. Histograms of $b_{\mathrm{abs}}(\mathrm{PSAP} ; \lambda=550 \mathrm{~nm}) / M_{\mathrm{BC}}(\mathrm{COSMOS})$ ratios at Alert for (a) 1-h averaged and (b) 24-h averaged data. Histograms for all data and data with $M_{\mathrm{BC}}(\mathrm{COSMOS})<10 \mathrm{ng} \mathrm{m}^{-}$ ${ }^{3}$ are shown. The interquartile ranges are shown in parentheses. 
(a)

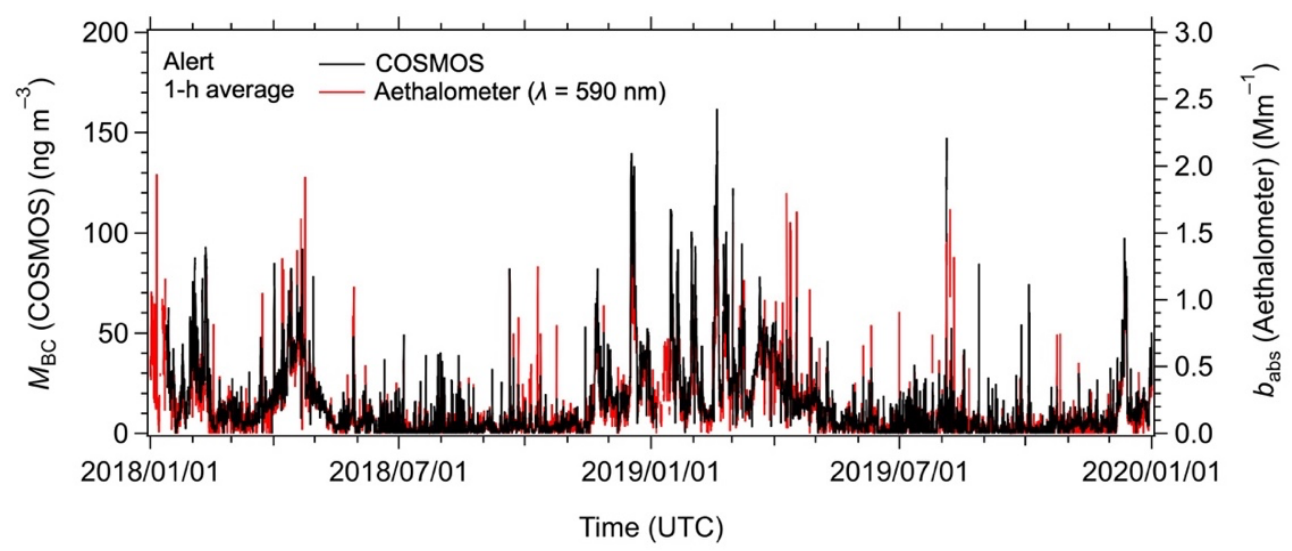

25
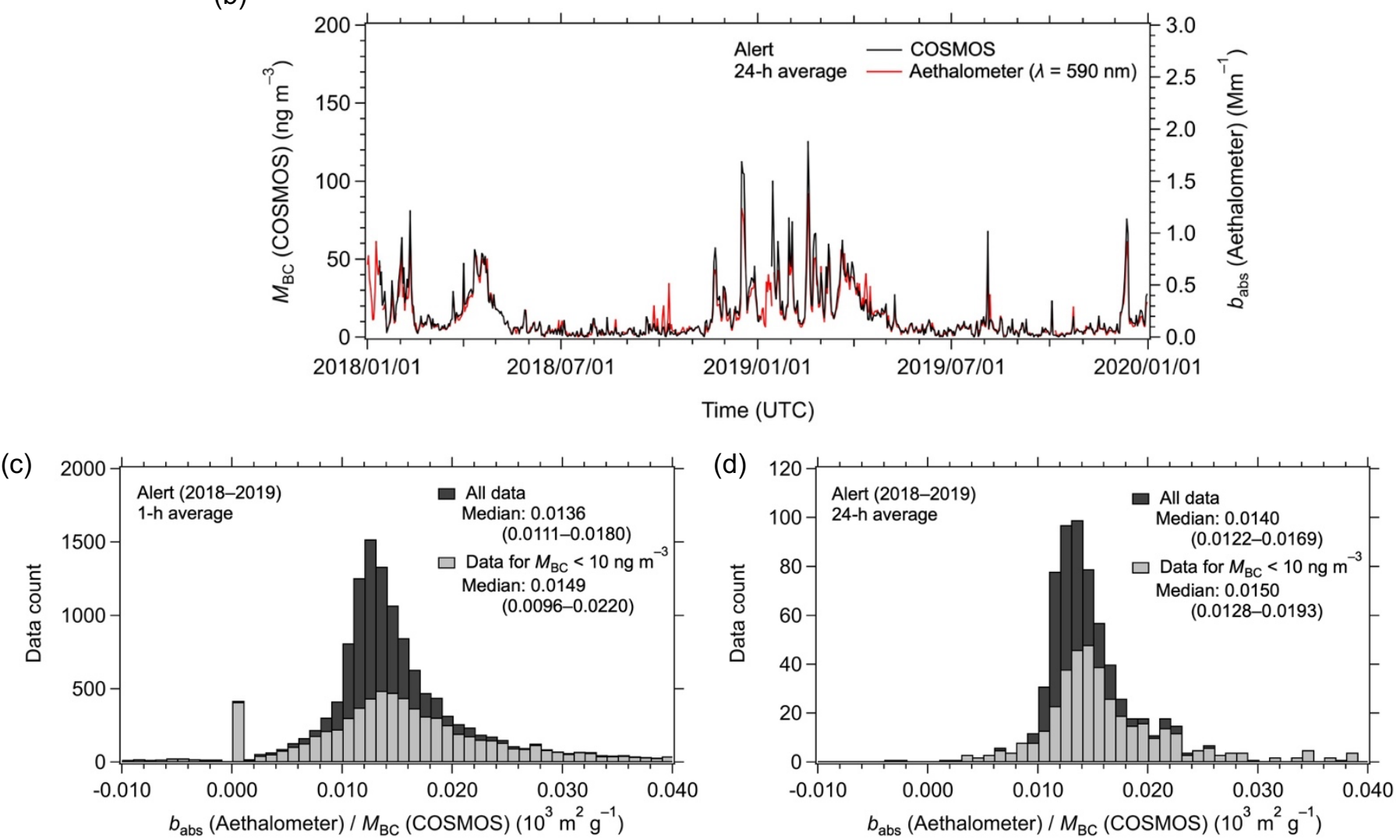

Figure S3. Time series of $M_{\mathrm{BC}}(\mathrm{COSMOS})$ and $b_{\text {abs }}$ (Aethalometer; $\lambda=590 \mathrm{~nm}$ ) from January 2018 to December 2019 at Alert for (a) 1-h averaged and (b) 24-h averaged data. (c) and (d) Corresponding histograms of $b_{\mathrm{abs}}$ (Aethalometer) / $M_{\mathrm{BC}}(\mathrm{COSMOS})$ ratios for all data and data with $M_{\mathrm{BC}}(\mathrm{COSMOS})<$ $10 \mathrm{ng} \mathrm{m}^{-3}$. The interquartile ranges are shown in parentheses. 
(a)

40

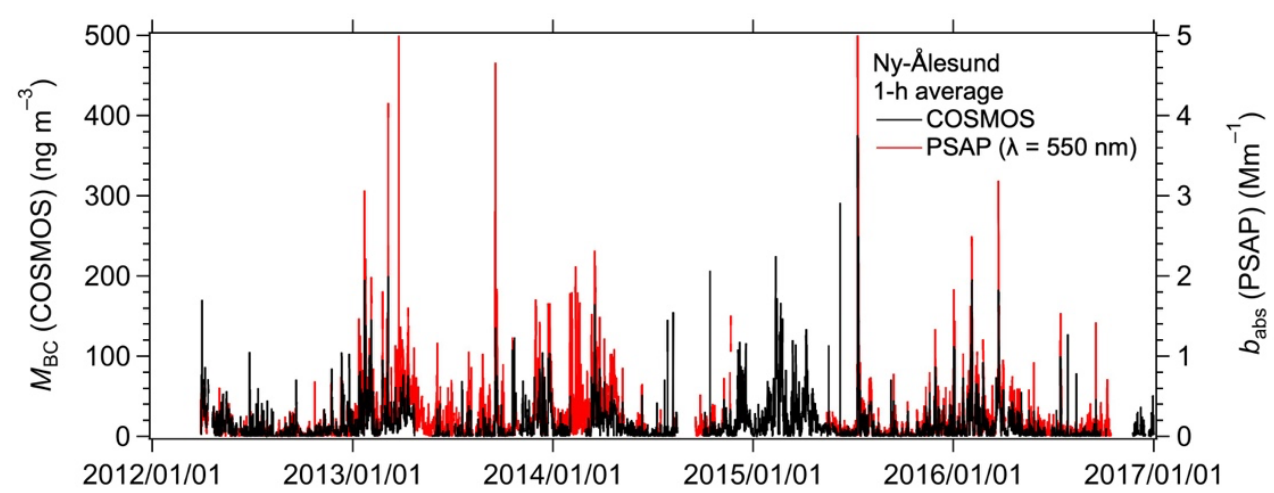

(b)

Time (UTC)

45

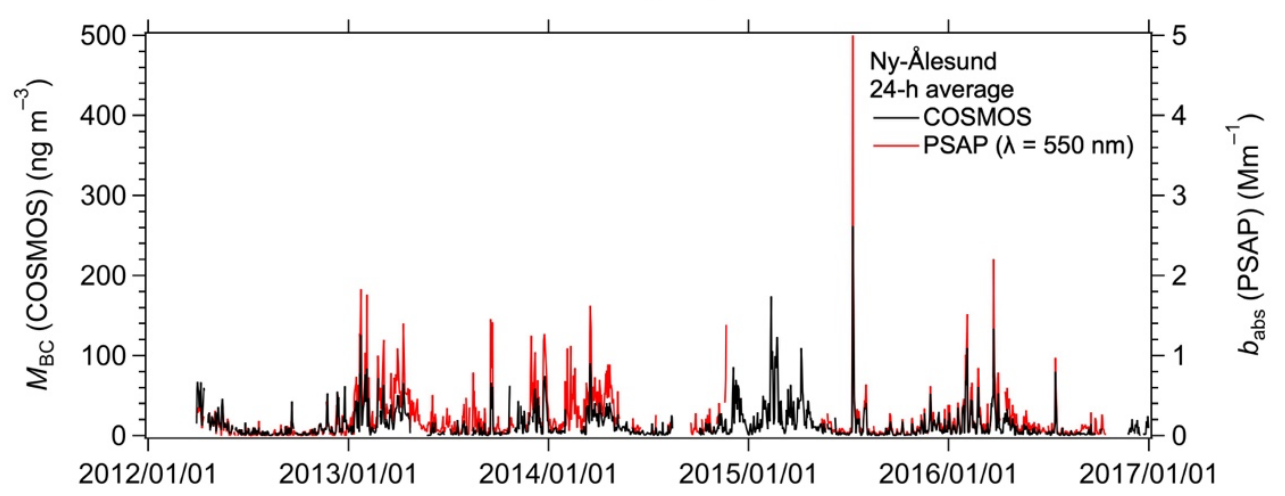

50

(c)

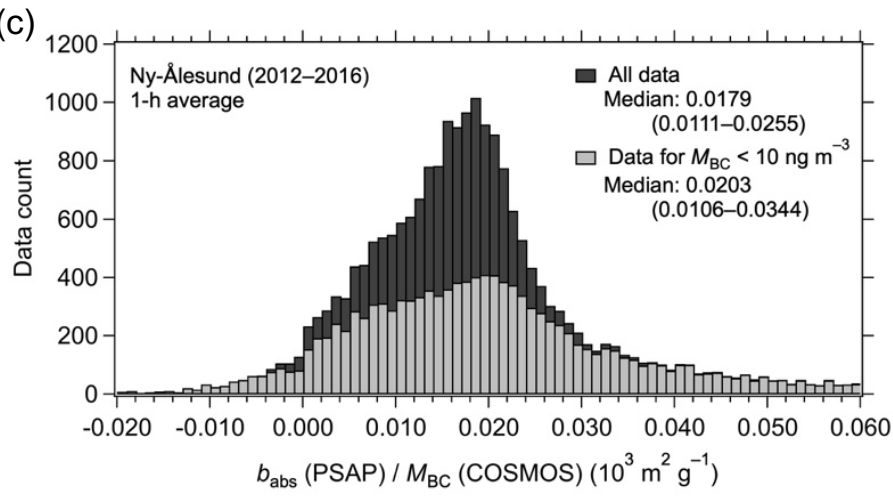

Time (UTC)

(d)

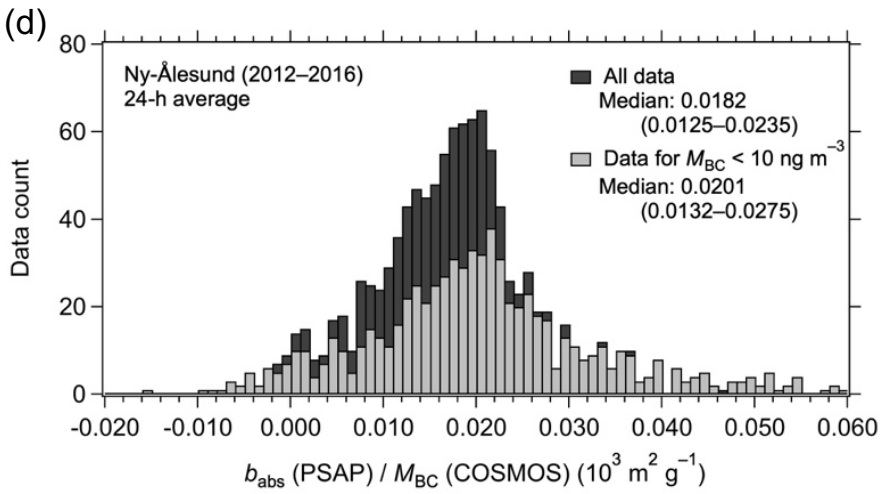

Figure S4. Time series of $M_{\mathrm{BC}}(\mathrm{COSMOS})$ and $b_{\mathrm{abs}}(\mathrm{PSAP} ; \lambda=550 \mathrm{~nm})$ from April 2012 to September 2016 at Ny-Ålesund for (a) 1-h averaged and (b) 24-h averaged data. (c) and (d) Corresponding histograms of $b_{\mathrm{abs}}(\mathrm{PSAP}) / M_{\mathrm{BC}}(\mathrm{COSMOS})$ ratios for all data and data with $M_{\mathrm{BC}}(\mathrm{COSMOS})<10 \mathrm{ng}$ $55 \mathrm{~m}^{-3}$. The interquartile ranges are shown in parentheses. 
(a)

60

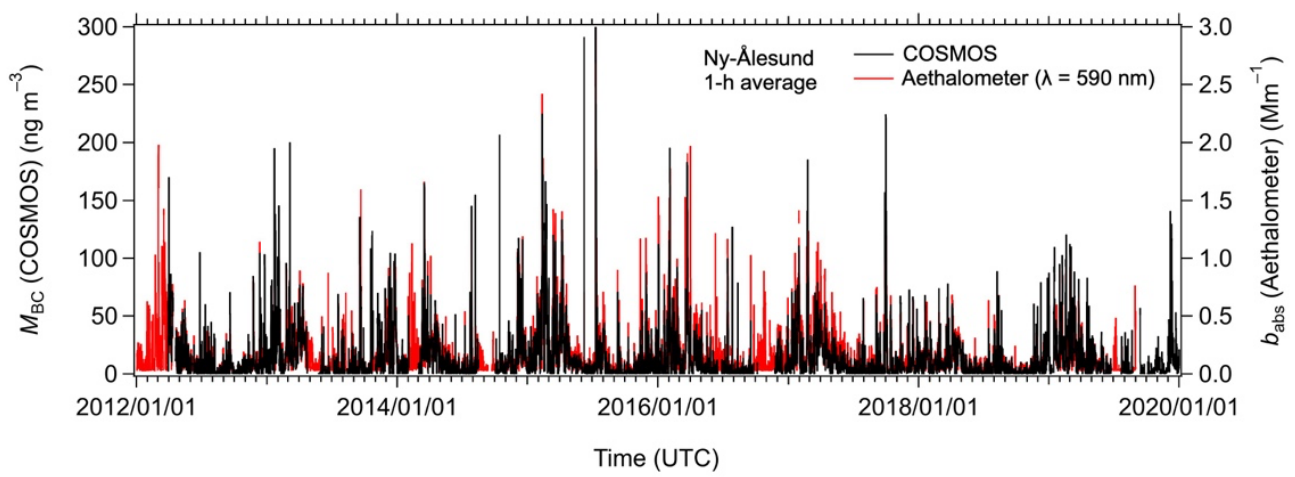

(b)
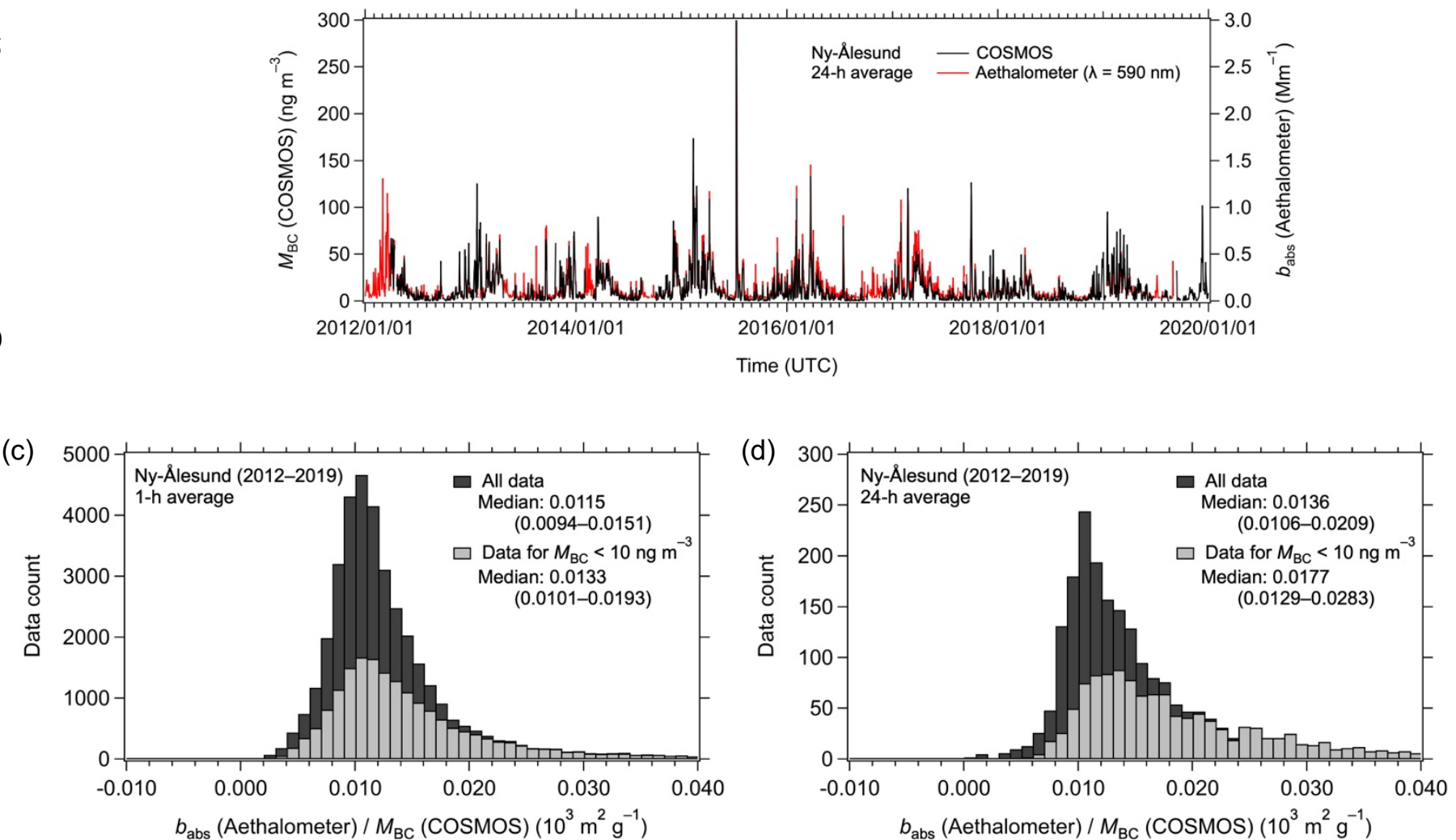

Figure S5. Time series of $M_{\mathrm{BC}}(\mathrm{COSMOS})$ and $b_{\mathrm{abs}}$ (Aethalometer; $\left.\lambda=590 \mathrm{~nm}\right) \mathrm{f}$ from April 2012 to August 2019 at Ny-Ålesund for (a) 1-h averaged and (b) 24-h averaged data. (c) and (d) Corresponding histograms of $b_{\mathrm{abs}}$ (Aethalometer) / $M_{\mathrm{BC}}(\mathrm{COSMOS})$ ratios for all data and data with $M_{\mathrm{BC}}(\mathrm{COSMOS})<$ $7510 \mathrm{ng} \mathrm{m}^{-3}$. The interquartile ranges are shown in parentheses. 
(a)

80

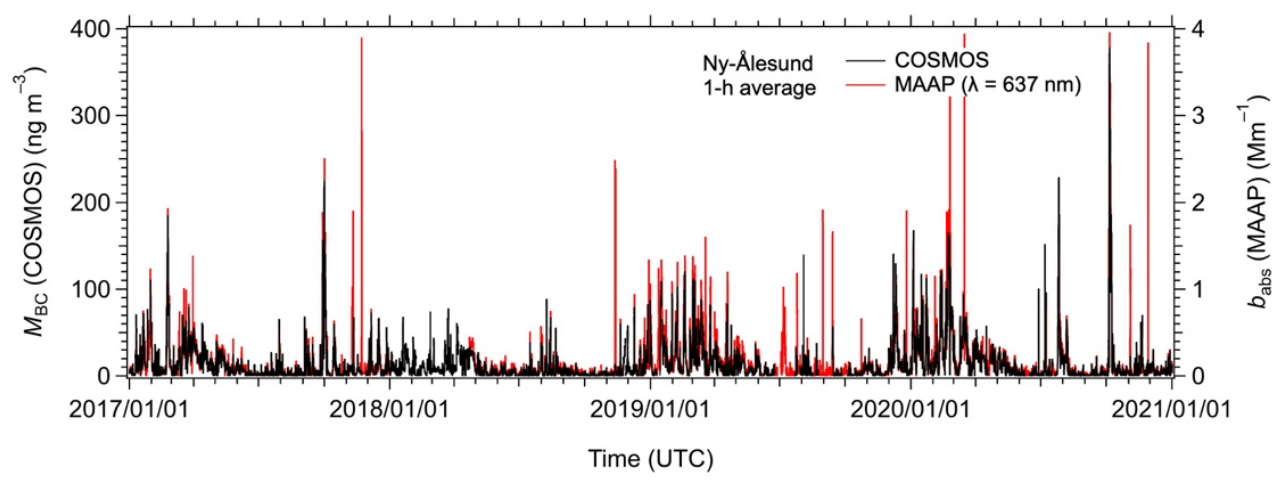

(b)
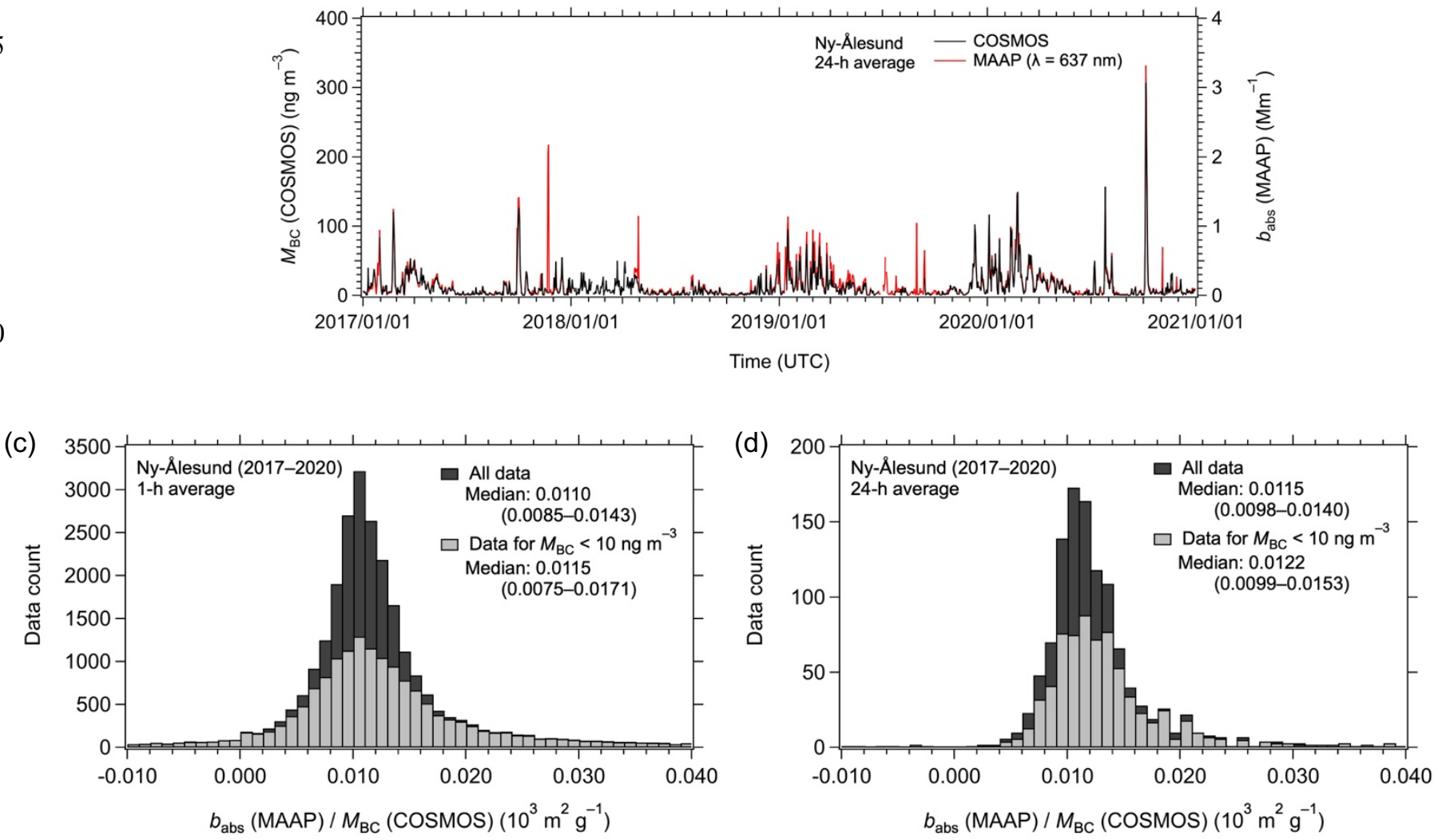

Figure S6. Time series of $M_{\mathrm{BC}}(\mathrm{COSMOS})$ and $b_{\mathrm{abs}}(\mathrm{MAAP} ; \lambda=637 \mathrm{~nm}$ ) from January 2017 to December 2020 at Ny-Ålesund for (a) 1-h averaged and (b) 24-h averaged data. (c) and (d) Corresponding histograms of $b_{\mathrm{abs}}(\mathrm{MAAP}) / M_{\mathrm{BC}}(\mathrm{COSMOS})$ ratios for all data and data with $M_{\mathrm{BC}}$ $95($ COSMOS $)<10 \mathrm{ng} \mathrm{m}^{-3}$. The interquartile ranges are shown in parentheses. 
(a)

100

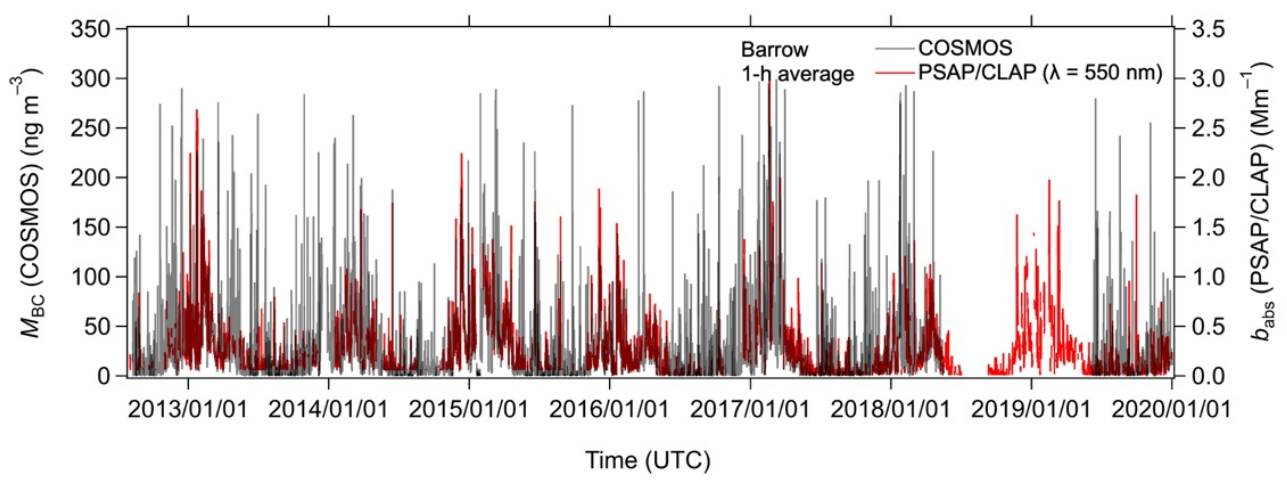

(b)

105

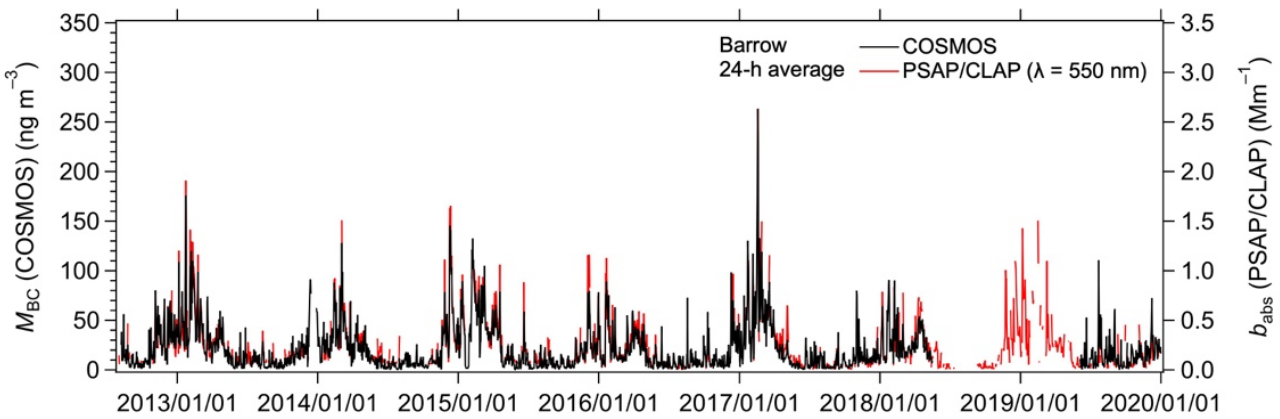

Time (UTC)
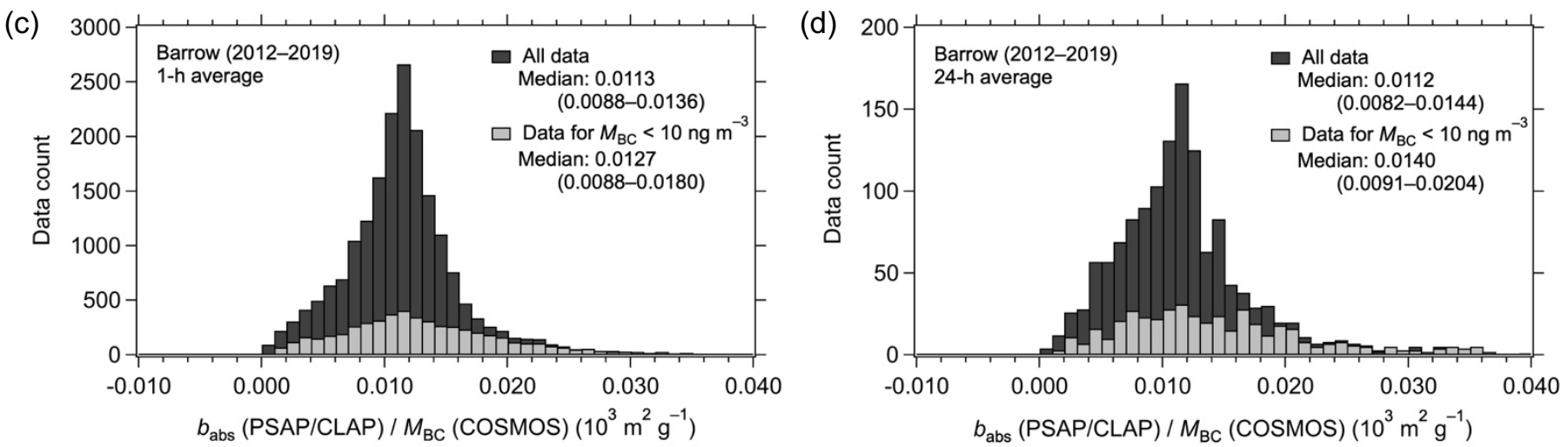

Figure S7. Time series of $M_{\mathrm{BC}}(\mathrm{COSMOS})$ and $b_{\mathrm{abs}}($ PSAP/CLAP; $\lambda=550 \mathrm{~nm})$ from August 2012 to December 2019 at Barrow for (a) 1-h averaged and (b) 24-h averaged data. (c) and (d) Corresponding histograms of $b_{\mathrm{abs}}(\mathrm{PSAP} / \mathrm{CLAP}) / M_{\mathrm{BC}}(\mathrm{COSMOS})$ ratios for all data and data with $M_{\mathrm{BC}}(\mathrm{COSMOS})<$ $11510 \mathrm{ng} \mathrm{m}^{-3}$. The interquartile ranges are shown in parentheses. 
(a)

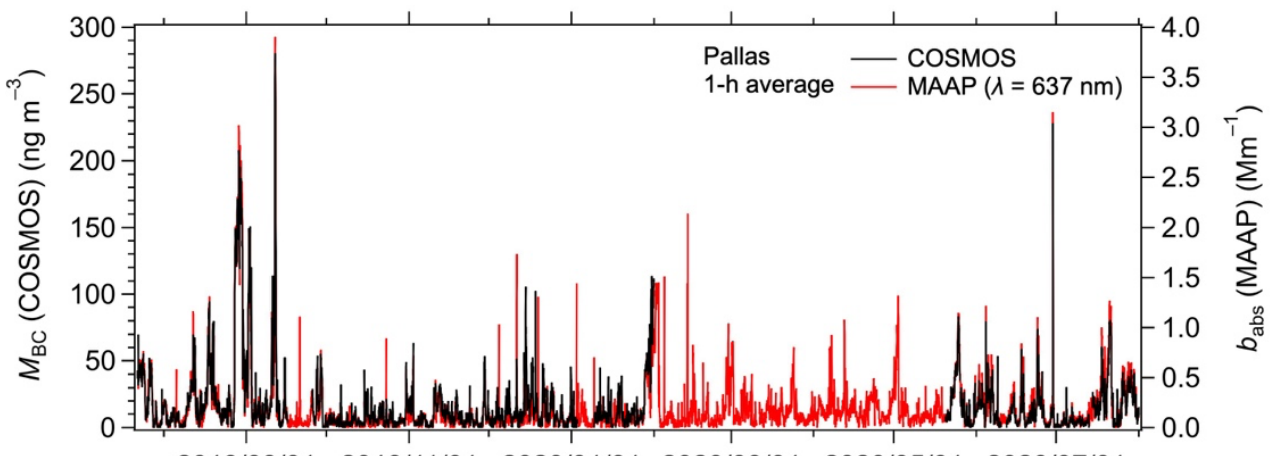

(b)

125

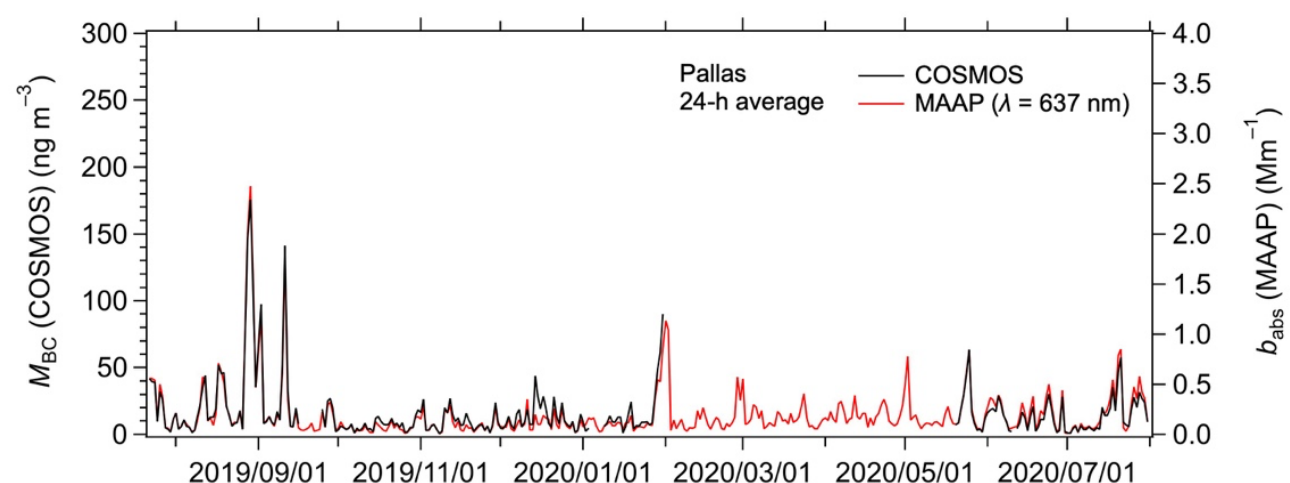

Local time

(c)

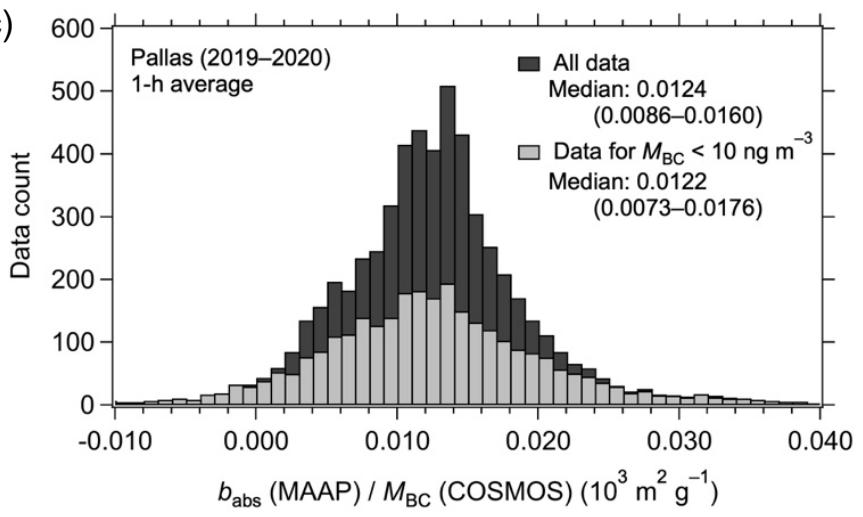

(d)

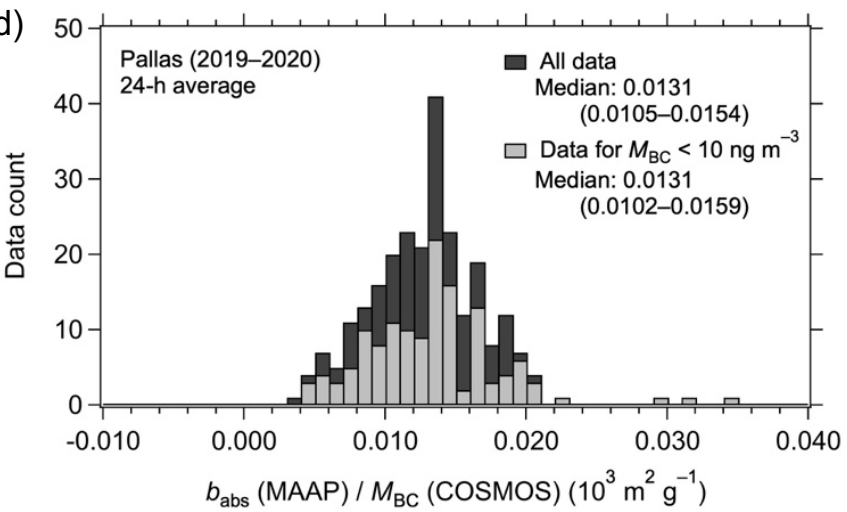

Figure S8. Time series of $M_{\mathrm{BC}}(\mathrm{COSMOS})$ and $b_{\mathrm{abs}}$ (MAAP; $\lambda=637 \mathrm{~nm}$ ) from July 2019 to July 2020 at Pallas for (a) 1-h averaged and (b) 24-h averaged data. (c) and (d) Corresponding histograms of $b_{\text {abs }}$ (MAAP) $/ M_{\mathrm{BC}}(\mathrm{COSMOS})$ ratios for all data and data with $M_{\mathrm{BC}}(\mathrm{COSMOS})<10 \mathrm{ng} \mathrm{m}^{-3}$. The 135 interquartile ranges are shown in parentheses. 
(a)

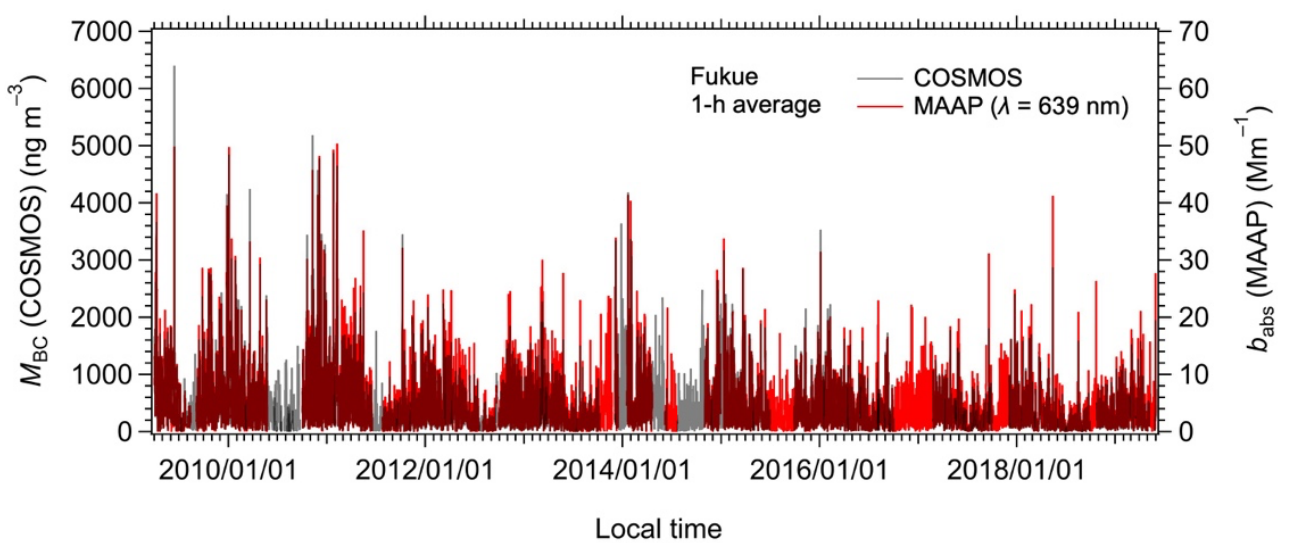

(b)

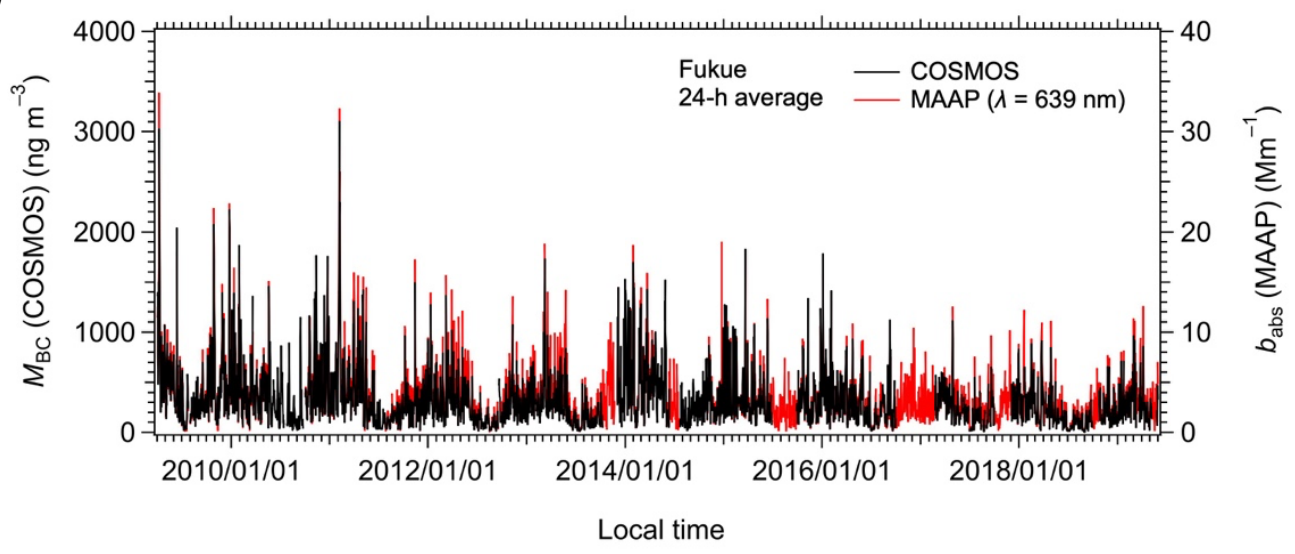

Figure S9. Time series of $M_{\mathrm{BC}}(\mathrm{COSMOS})$ and $b_{\mathrm{abs}}(\mathrm{MAAP} ; \lambda=590 \mathrm{~nm}$ ) from April 2009 to May 2019 at Fukue for (a) 1-h averaged and (b) 24-h averaged data. 